\title{
Polymorphisms in FTO, TMEM18 and PCSK1 are associated with BMI in southern Chinese population
}

\author{
JIE CHEN ${ }^{1}$, MEI YANG ${ }^{1}$, KEHUI ZHAO $^{1}$, AIMIN XU $^{2}$ and QINGYANG HUANG ${ }^{1 *}$ \\ ${ }^{1}$ College of Life Sciences, Central China Normal University, Wuhan 430079, People's Republic of China \\ ${ }^{2}$ Li Ka Shing Faculty of Medicine, The University of Hong Kong, Pokfulam, Hong Kong
}

[Chen J., Yang M., Zhao K., Xu A. and Huang Q. 2014 Polymorphisms in FTO, TMEM18 and PCSK1 are associated with BMI in southern Chinese population. J. Genet. 93, 509-512]

\section{Introduction}

Obesity is a major health problem in the world, and is defined as excessive fat accumulation and quantified by body mass index (BMI). Genetic factors play a key role in obesity. In the last few years, genomewide association studies (GWAS) have produced a number of novel genes and polygenic variants associated putatively with obesity. Common variants at FTO, INSIG2 and MC4R loci were previously reported to be associated with fat mass, weight and obesity in several populations (Sandholt et al. 2010). Yanagiya et al. (2007) revealed that genetic variations in MTMR9 may confer a predisposition towards obesity. PCSK1 was also firmly placed on the short list of genes reproducibly associated with common obesity (Benzinou et al. 2008). A meta-analysis of 15 GWAS performed by the GIANT consortium on total 32,387 individuals of European ancestry discovered that six previously unreported loci in or near KCTD15, SH2B1, GNPDA2, TMEM18, NEGR1 and MTCH2 are associated with BMI (Willer et al. 2009).

In this study, we attempt to examine the association between BMI and the genes mentioned here by genotyping the previously reported 11 single-nucleotide polymorphism (SNP) in southern Chinese.

\section{Materials and methods}

\section{Subjects}

This study included 1560 southern Chinese individuals (288 men and 1272 women) with mean age of $49.8 \pm 15.9$ years (women, $49.5 \pm 15.9$, men, $50.9 \pm 15.9$ ), mean height of $1.57 \pm 0.08 \mathrm{~m}$ (women, $1.55 \pm 0.07$, men, $1.67 \pm 0.07$ ),

*For correspondence. E-mail: huangqy@mail.ccnu.edu.cn. and mean weight of $55.7 \pm 10.8 \mathrm{~kg}$ (women, $53.4 \pm 9.3$, men, $53.4 \pm 9.3$ ). A detailed description of subject ascertainment, inclusion and exclusion criteria has been described previously ( $\mathrm{Ng}$ et al. 2006). BMI was calculated as weight $(\mathrm{kg}) /$ height $^{2}\left(\mathrm{~m}^{2}\right)$.

\section{SNP selection and genotyping}

Eleven SNPs from 10 candidate genes (FTO, KCTD15, INISG2, SH2B1, PCSK1, MTMR9, GNPDA2, TMEM18, $M C 4 R$ and NEGR1), which have been reported to be associated with BMI, were selected for genotyping in 1560 subjects using the high-throughput mass array technology. Five percent of samples were duplicated for quality check in the genotyping process and the reproducibility rate exceeded $99.8 \%$.

\section{Statistical analysis}

Since the raw data of BMI deviated from normal distribution, a square root transformation was conducted. GenotypeBMI association analyses were performed by linear regression, SNP being coded as 0,1 and 2 according to genotypes. Analyses included linear regression of single SNP (adjusted with age) with BMI and multiple stepwise regressions of 11 SNPs, and age with BMI. Statistical analyses were performed using SPSS 11.5 for Windows software. A $P$ value less than 0.05 was considered to be statistically significant.

\section{Results and discussion}

The BMI in our samples ranged from 14.97 to $37.95 \mathrm{~kg} / \mathrm{m}^{2}$. Kolmogorov-Smirnov test suggested that the distribution of BMI deviated from normal distribution $(P=0.001)$, but square root of BMI (sqrt BMI) followed normal distribution $(P=0.056)$ (figure 1$)$.

Keywords. association; FTO; TMEM18; PCSK1; BMI. 
Jie Chen et al.

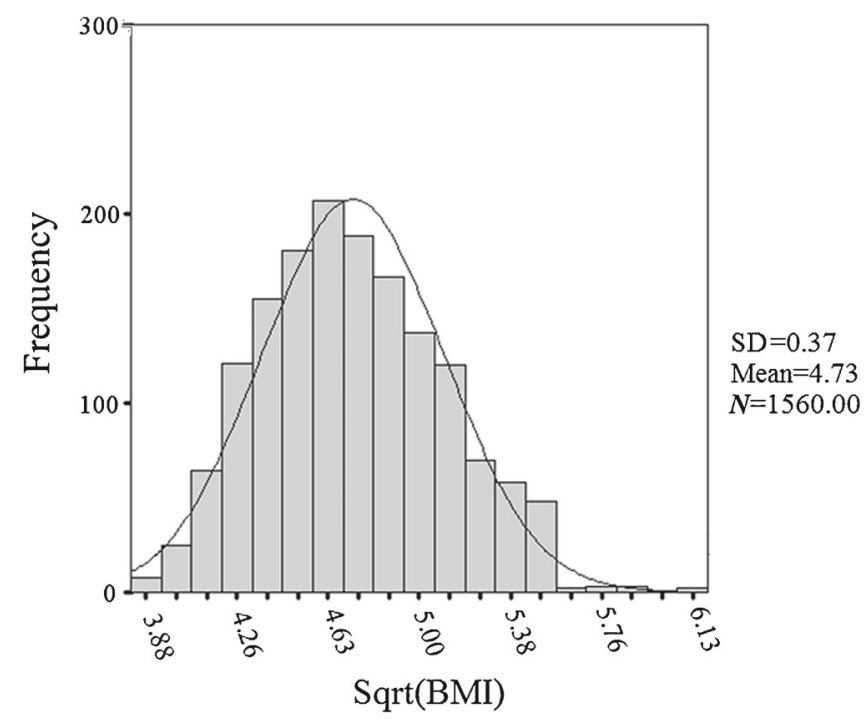

Figure 1. Histogram graph with normal curve of sqrt (BMI).

Linear regression between single SNP and age, and square root of BMI was performed (table 1). Significant partial regression coefficient were found for FTO rs9939609 $(P=0.004)$ and TMEM18 $\operatorname{rs6548238}(P=0.003)$. KCTD15 (rs11084753), PCSK1 (rs6234, rs6235), MTMR9 (rs2293855) and NEGR1 (rs2815752) showed a weak correlation with BMI. For FTO rs9939609, BMI of AA $\left(23.25 \mathrm{~kg} / \mathrm{m}^{2}\right)$ and AT $\left(22.87 \mathrm{~kg} / \mathrm{m}^{2}\right)$ genotypes were significantly higher than those of TT $\left(22.35 \mathrm{~kg} / \mathrm{m}^{2}\right)$ genotype $(P=0.010)$. It seems that the A allele increases BMI in dominant model. For rs6548238 (TMEM18), there is significant difference in BMI between CC $\left(22.60 \mathrm{~kg} / \mathrm{m}^{2}\right)$ and TC $\left(21.98 \mathrm{~kg} / \mathrm{m}^{2}\right)$ genotype $(P=0.015)$. TT genotype had the lowest BMI $\left(20.84 \mathrm{~kg} / \mathrm{m}^{2}\right)$. Multiple stepwise regression equation of BMI on $11 \mathrm{SNPs}$ and age included FTO, TMEM18 and PCSK1 genes: sqrt BMI $=4.216+0.065 \mathrm{x}_{1}$ $($ rs6548238, $P=0.007)+0.058 \mathrm{x}_{2}($ rs $9939609, P=0.002)$ $+0.030 \mathrm{x}_{3}(\mathrm{rs} 6234, P=0.031)+0.007 \mathrm{x}_{4}($ age $), R^{2}=10.4 \%$.

Subgroup analyses were also performed to examine gender difference of obesity genetics. For women, apart from
FTO rs9939609 $(P=0.006)$ and TMEM18 rs6548238 $(P=0.007)$, an association was found between GNPDA2 rs $10938397(P=0.014)$ and BMI. For men, only MC4R rs 17782313 was associated with BMI $(P=0.034)$. Causes for gender difference included sex-specific genetic control and small sample size of men's subgroup.

FTO, located on chromosome 16q12.2, was earliest identified as a susceptible locus for obesity. rs9939609 in FTO was identified to be predisposed to diabetes through an effect on BMI in a genomewide search for type 2 diabetes, and then first reported as obesity susceptibility gene (Sandholt et al. 2012). In two ongoing longitudinal studies, Liu et al. (2011) assessed the influence of rs9939609 on development of adiposity in European-American and African-American youth, and found that rs 9939609 was associated with $\log B$ MI. So far, six studies have been published on rs9939609 locus of FTO in Chinese populations. Although two studies found no association of rs9939609 variant with obesity (Li et al. 2008; Yan et al. 2009), rs9939609 is associated with BMI in ethnic Chinese in Singapore (Tan et al. 2008), Chinese children (Fang et al. 2010), Taiwan Chinese Han populations (Chang et al. 2008) and Hubei Han Chinese aged from 50-70 years (Huang et al. 2011). Our current study successfully replicated association between FTO rs9939609 and BMI in southern Chinese from Hong Kong. Four meta-analyses of associations between rs9939609 and obesity / BMI have been published in recent years and FTO rs9939609 was significantly associated with BMI (Xi and Mi 2009; Liu et al. 2010; Chauhan et al. 2011; Li et al. 2012).

TMEM18-associated SNPs were first found to be associated with obesity by two GWAS (Willer et al. 2009; Thorleifsson et al. 2009). From then on, the association with obesity was confirmed on Swedish children (Almén et al. 2010), Greek (Rouskas et al. 2012) and Japanese populations (Takeuchi et al. 2011) and children and adolescents from Denmark and Estonia (Den Hoed et al. 2010). Although two previous studies found no association of TMEM18 polymorphisms with BMI in Chinese populations (Ng et al. 2010; Huang et al. 2012), our study demonstrated that rs6548238 was associated with BMI in southern Chinese aged 18-85

Table 1. Association of 11 loci with BMI in southern Chinese population.

\begin{tabular}{llccl}
\hline Gene & SNP (normal allele / risk allele) & Regression equation & $R^{2}$ & $P$ \\
\hline GNPDA2 & $\mathrm{rs} 10938397(\mathrm{~A} / \mathrm{G})$ & $\mathrm{y}=4.367+0.023 \mathrm{x}_{1}+0.007 \mathrm{x}_{2}$ & $8.9 \%$ & 0.107 \\
FTO & $\mathrm{rs} 9939609(\mathrm{~T} / \mathrm{A})$ & $\mathrm{y}=4.367+0.054 \mathrm{x}_{1}+0.007 \mathrm{x}_{2}$ & $9.2 \%$ & $0.004^{*}$ \\
INSIG2 & $\mathrm{rs} 7566605(\mathrm{G} / \mathrm{C})$ & $\mathrm{y}=4.374+0.009 \mathrm{x}_{1}+0.007 \mathrm{x}_{2}$ & $8.8 \%$ & 0.505 \\
KCTD15 & $\mathrm{rs} 11084753(\mathrm{~A} / \mathrm{G})$ & $\mathrm{y}=4.362+0.028 \mathrm{x}_{1}+0.007 \mathrm{x}_{2}$ & $9.0 \%$ & 0.053 \\
MC4R & $\mathrm{rs} 17782313(\mathrm{~T} / \mathrm{C})$ & $\mathrm{y}=4.371+0.027 \mathrm{x}_{1}+0.007 \mathrm{x}_{2}$ & $9.0 \%$ & 0.126 \\
MTMR9 & $\mathrm{rs} 2293855(\mathrm{~A} / \mathrm{G})$ & $\mathrm{y}=4.367+0.025 \mathrm{x}_{1}+0.007 \mathrm{x}_{2}$ & $9.0 \%$ & 0.078 \\
NEGR1 & $\mathrm{rs} 2815752(\mathrm{C} / \mathrm{T})$ & $\mathrm{y}=4.315+0.037 \mathrm{x}_{1}+0.007 \mathrm{x}_{2}$ & $9.0 \%$ & 0.088 \\
PCSK1 & $\mathrm{rs} 6234(\mathrm{C} / \mathrm{G})$ & $\mathrm{y}=4.362+0.024 \mathrm{x}_{1}+0.007 \mathrm{x}_{2}$ & $9.1 \%$ & 0.080 \\
PCSK1 & $\mathrm{rs} 6235(\mathrm{G} / \mathrm{C})$ & $\mathrm{y}=4.361+0.026 \mathrm{x}_{1}+0.007 \mathrm{x}_{2}$ & $9.1 \%$ & 0.054 \\
SH2B1 & $\mathrm{rs} 7498665(\mathrm{G} / \mathrm{A})$ & $\mathrm{y}=4.356+0.014 \mathrm{x}_{1}+0.007 \mathrm{x}_{2}$ & $8.8 \%$ & 0.544 \\
TMEM18 & $\mathrm{rs} 6548238(\mathrm{~T} / \mathrm{C})$ & $\mathrm{y}=4,248+0.071 \mathrm{x}_{1}+0.007 \mathrm{x}_{2}$ & $9.4 \%$ & $0.003 *$ \\
\hline
\end{tabular}

$\mathrm{x}_{1}(\mathrm{SNP}), \mathrm{x}_{2}$ (age), $* P<0.05$. 
years. In addition, a study on Chinese children (10-20 years aged boys) from Shanghai also validated that rs6548238 in TMEM18 has an association with obesity-related indices during puberty (Wang et al. 2012). A recent research has shown that TMEM18 plays a regulatory role in human adipocyte differentiation (Bernhard et al. 2013).

PCSK1 encodes prohormone convertase 1/3 which can convert inactive prohormones into biologically active peptide hormones. Loss-of-function mutations in PCSK1 give rise to monogenic obesity (Jackson et al. 1997). Benzinou et al. (2008) initially uncovered rs6232 and rs6234-rs6235 in PCSK 1 strongly associated with obesity risk among adults and children in European populations. Association of rs6232 and rs6235 with obesity, and BMI were also replicated in European (Kilpeläinen et al. 2009; Sandholt et al. 2010; Rouskas et al. 2012) and Mexican populations (Villalobos et al. 2012). Here, our study demonstrated that rs6234 was associated with BMI in Chinese.

Our present study demonstrated that FTO-rs9939609, TMEM18-rs6548238 and PCSK1-rs6234 polymorphisms are significantly associated with BMI in southern Chinese population. However, we are unable to replicate the associations for other loci; due to small sample size and limited statistical power.

\section{Acknowledgements}

This work was supported by National Basic Research Program of China (973 programme, no. 2011CB504004) and selfdetermined research funds of CCNU from the colleges' basic research and operation of MOE.

\section{References}

Almén M. S., Jacobsson J. A., Shaik J. H., Olszewski P. K., Cedernaes J., Alsiö J. et al. 2010 The obesity gene, TMEM18, is of ancient origin, found in majority of neuronal cells in all major brain regions and associated with obesity in severely obese children. BMC Med. Genet. 11, 58.

Benzinou M., Creemers J. W., Choquet H., Lobbens S., Dina C., Durand E. et al. 2008 Common nonsynonymous variants in PCSK1 confer risk of obesity. Nat. Genet. 40, 943-945.

Bernhard F., Landgraf K., Kloting N., Berthold A., Buttner P., Friebe D. et al. 2013 Functional relevance of genes implicated by obesity genome-wide association study signals for human adipocyte biology. Diabetologia 56, 311-322.

Chang Y. C., Liu P. H., Lee W. J., Chang T. J., Jiang Y. D., Li H. Y. et al. 2008 Common variation in the fat mass and obesityassociated (FTO) gene confers risk of obesity and modulates BMI in the Chinese population. Diabetes 57, 2245-2252.

Chauhan G., Tabassum R., Mahajan A., Dwivedi O. P., Mahendran Y., Kaur I. et al. 2011 Common variants of FTO and the risk of obesity and type 2 diabetes in Indians. J. Hum. Genet. 56, $720-726$.

Den Hoed M., Ekelund U., Brage S., Grontved A., Zhao J. H., Sharp S. J. et al. 2010 Genetic susceptibility to obesity and related traits in childhood and adolescence: influence of loci identified by genome-wide association studies. Diabetes 59, 2980 2988.
Fang H., Li Y., Du S., Hu X., Zhang Q., Liu A. et al. 2010 Variant rs9939609 in the FTO gene is associated with body mass index among Chinese children. BMC Med. Genet. 11, 136.

Huang H., Zeng Z., Zhang L., Liu R., Li X., Qiang O. et al. 2012 Implication of genetic variants near TMEM18, $B C D I N 3 D / F A I M 2$, and $M C 4 R$ with coronary artery disease and obesity in Chinese: a angiography-based study. Mol. Biol. Rep. 39, 1739-1744.

Huang W., Sun Y. and Sun J. 2011 Combined effects of FTO rs9939609 and MC4R rs17782313 on obesity and BMI in Chinese Han populations. Endocrine 39, 69-74.

Jackson R. S., Creemers J. W., Ohagi S., Raffin-Sanson M. L., Sanders L., Montague C. T. et al. 1997 Obesity and impaired prohormone processing associated with mutations in the human prohormine convertase 1 gene. Nat. Genet. 16, 303306.

Kilpeläinen T. O., Bingham S. A., Khaw K. T., Wareham N. J. and Loos R. J. 2009 Association of variants in the PCSK1 gene with obesity in the EPIC-Norfolk study. Hum. Mol. Genet. 18, 34963501 .

Li H., Wu Y., Loos R. J., Hu F. B., Liu Y., Wang J. et al. 2008 Variants in the fat mass- and obesity-associated (FTO) gene are not associated with obesity in a Chinese Han population. Diabetes 57, 264-268.

Li H., Kilpeläinen T. O., Liu C., Zhu J., Liu Y., Hu C. et al. 2012 Association of genetic variation in FTO with risk of obesity and type 2 diabetes with data from 96,551 East and South Asians. Diabetologia 55, 981-995.

Liu Y., Liu Z., Song Y., Zhou D., Zhang D., Zhao T. et al. 2010 Meta-analysis added power to identify variants in FTO associated with type 2 diabete and obesity in the Asian population. Obesity 18, 1619-1624.

Liu G., Zhu H., Dong Y., Podolsky R. H., Treiber F. A. and Snieder H. 2011 Influence of common variants in FTO and near INSIG2 and MC4R on growth curves for adiposity in Africanand European-American youth. Eur. J. Epidemiol. 26, 463473.

Ng M. C., Tam C. H., So W. Y., Ho J. S., Chan A. W., Lee H. M. et al. 2010 Implication of genetic variants near NEGR1, SEC16B, TMEM18, ETV5/DGKG, GNPDA2, LIN7C/BDNF, MTCH2, BCDIN3D/FAIM2, SH2B1, FTO, MC4R, and KCTD15 with obesity and type 2 diabetes in 7705 Chinese. J. Clin. Endocrinol. Metab. 95, 2418-2425.

Ng M. Y., Sham P. C., Paterson A. D., Chan V. and Kung A. W. 2006 Effect of environmental factors and gender on the heritability of bone mineral density and bone size. Ann. Hum. Genet. 70, 428438.

Rouskas K., Kouvatsi A., Paletas K., Papazoglou D., Tsapas A., Lobbens S. et al. 2012 Common variants in FTO, MC4R, TMEM18, PRL, AIF1, and PCSK1 show evidence of association with adult obesity in the Greek population. Obesity 20,389395.

Sandholt C. H., Sparsø T., Grarup N., Albrechtsen A., Almind K., Hansen L. et al. 2010 Combined analyses of 20 common obesity susceptibility variants. Diabetes 59, 1667-1673.

Sandholt C. H., Hansen T. and Pedersen O. 2012 Beyond the fourth wave of genome-wide obesity association studies. Nutr. Diabet. 2, e37.

Takeuchi F., Yamamoto K., katsuya T., Nabika T., Sugiyama T., Fujioka A. et al. 2011 Association of genetic variants for susceptibility to obesity with type 2 diabetes in Japanese individuals. Diabetologia 54, 1350-1359.

Tan J. T., Dorajoo R., Seielstad M., Sim X. L., Ong R. T., Chia K. S. et al. 2008 FTO variants are associated with obesity in the Chinese and Malay populations in Singapore. Diabetes 57, 28512857. 
Thorleifsson G., Walters G. B., Gudbjartsson D. F., Steinthorsdottir V., Sulem P., Helgadottir A. et al. 2009 Genome-wide association yields new sequence variants at seven loci that associate with measures of obesity. Nat. Genet. 41, 18-24.

Villalobos C. M., Villamil R. H., Villarreal M. T., Larrieta C. E., León M. P., Romero H. S. et al. 2012 PCSK1 rs6232 is associated with childhood and adult class III obesity in the Mexican population. PLoS One 7, 39037.

Wang J., Mei H., Chen W., Jiang Y., Sun W., Li F. et al. 2012 Study of eight GWAS-identified common variants for association with obesity-related indices in Chinese children at puberty. Int. J. Obes. 36, 542547.
Willer C. J., Speliotes E. K., Loos R. J., Li S., Lindgren C. M., Heid I. M. et al. 2009 Six new loci association with body mass index highlight a neuronal influence on body weight regulation. Nat. Genet. 41, 25-34.

Xi B. and Mi J. 2009 FTO polymorphisms are associated with obesity but not with diabetes in East Asian populations: a metaanalysis. Biomed. Environ. Sci. 22, 449-457.

Yan Q., Hong J., Gu W., Zhang Y., Liu Q., Su Y. et al. 2009 Association of the common rs9939609 variant of FTO gene with polycystic ovary syndrome in Chinese women. Endocrine 36, 377382.

Yanagiya T., Tanabe A., Iida A., Saito S., Sekine A., Takahashi A. et al. 2007 Association of single-nucleotide polymorphisms in MTMR9 gene with obesity. Hum. Mol. Genet. 16, 3017-3026.

Received 25 November 2013, in revised form 12 January 2014; accepted 21 January 2014

Unedited version published online: 18 June 2014

Final version published online: 5 August 2014 